This is a preprint of a paper intended for publication in a journal or proceedings. Since changes may be made before publication, this preprint is made avaulable with the understanding that it will not be cited or reproduced without the permission of the author.

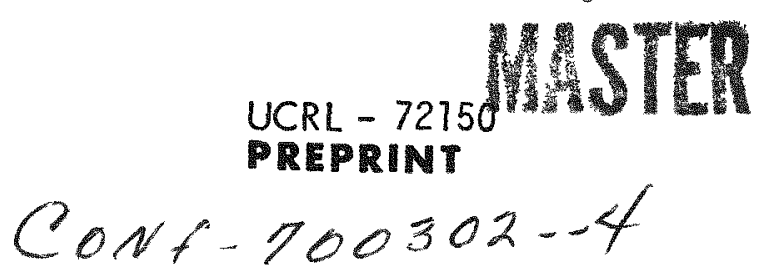

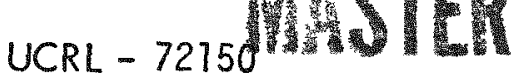

CONF-700302-4

LIVERMORE

OBSERVATIONS OF THE ELECTROMAGNETIC SIGNALS

FROM HIGH EXPLOSIVE DETONATION

C. W. Walker

February 10,1970

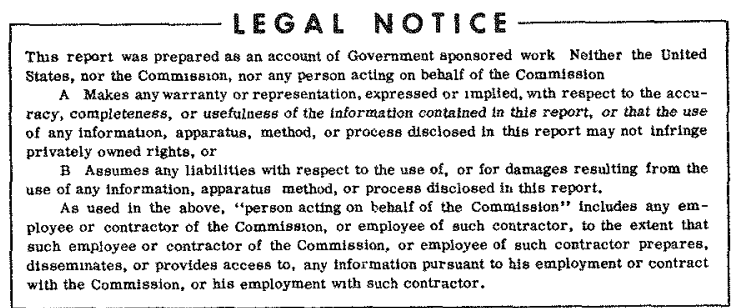

Symposium Proceedings

AFSWC Symposium, Albuquerque, New Mexico

March 12-13, 1970 


\section{DISCLAIMER}

This report was prepared as an account of work sponsored by an agency of the United States Government. Neither the United States Government nor any agency Thereof, nor any of their employees, makes any warranty, express or implied, or assumes any legal liability or responsibility for the accuracy, completeness, or usefulness of any information, apparatus, product, or process disclosed, or represents that its use would not infringe privately owned rights. Reference herein to any specific commercial product, process, or service by trade name, trademark, manufacturer, or otherwise does not necessarily constitute or imply its endorsement, recommendation, or favoring by the United States Government or any agency thereof. The views and opinions of authors expressed herein do not necessarily state or reflect those of the United States Government or any agency thereof. 


\section{DISCLAIMER}

Portions of this document may be illegible in electronic image products. Images are produced from the best available original document. 


\title{
OBSERVATIONS OF THE ELECTROMAGNETIC SIGNALS * FROM HIGH EXPLOSIVE DETONATION
}

\author{
C. W. Walker \\ Lawrence Radiation Laboratory, University of California \\ Livermore, California
}

New data have been added to the information available on electromagnetic signals generated during high explosive detonations. These include high speed motion picture photographs which give evidence of longer-time (millisecond) oscillations in the expanding plasma cloud. There is an identifiable correspondence with features of the electromagnetic waveforms as sensed and recorded using broad-band equipment. The configurations of high explosives used consisted mainly of vertically-suspended $1.3 \mathrm{Kgm}$ cylinders of composition B-3 in various height-to-diameter ratios. Some of these were similar to the test shapes described in recently published Soviet work.

The waveforms vary with the explosive configuration; field magnitudes of order ten $\mathrm{V} / \mathrm{m}$ at distances of twe lve meters were observed. In general, these tests substantiate Soviet results regarding geometrical shape dependence.

A special electro-optical detonation unit was developed to electromagnetically isolate the high explosive. Safety fuse, ordinary prima-cord, and lead-covered prima-cord detonation trains were also employed in studying the geometric effects of firing systems.

1 EM Disturbances in Explosions: Goshunov, Kononenko and Sirotinin (ATD 68-88)

* Work performed under the auspices of the U.S. Atomic Energy Commission. 


\section{OBSERVATIONS OF THE ELECTROMAGNETIC SIGNALS \\ FROM HIGH EXPLOSIVE DETONATION}

C. W. Walker

February 10, 1970

\section{Introduction and Purpose}

This investigation was concerned with the characteristics of the electromagnetic signal created by explosion of suspended Composition B-3 charges with constant mass but with different geometries. The charge shape parameters studied included four cylinders (Ht./Dia. ratios of 4.6, 2.0, 1.0 and 0.5 ) and two spheres (diameters of $11.5 \mathrm{~cm}$ and $23.0 \mathrm{~cm}$ ). Although the mass, detonation method, suspension height of the charge, and distance to the signa1-detecting antenna a 11 remained constant throughout the main portion of the experiment, a small-scale parameter study was also made of charge mass and suspension height. In general, these studies substantiate Soviet results ${ }^{1}$ regarding geometrical shape dependence. The available data ${ }^{2,3}$ was extended through the addition of synchronous high speed motion picture records and of a specially developed detonation unit that electromagnetically isolates the high explosive region. The information acquired furnishes sufficient input for preliminary source model studies.

This report primarily covers the experimental work and thus is divided into brief individual sections on the experimental layout, the details of the high explosive, the photographic and electronic instrumentation, the results (both graphical and motion picture slips) and some interpretations and discussion on a few of the results.

\section{Experimental Layout}

A depiction of the typical experimental arrangement for an explosive event appears in Fig. 1 (charge dimension exaggerated). Views of an event prior to firing and of the instrumentation bunker are exhibited in Fig. 2, 3, and Fig. 4, respectively. 
High Explosive

A photograph of the Composition B-3 charge in Fig. 5 illustrates the shapes studied; in these the tetryl detonation assembly was glued to one end of each cylinder. The sphere (with its affixed lead-covered primacord detonator), had a diameter of $11.5 \mathrm{~cm}$, while the tallest cylinder had a height/diameter ratio of $28 \mathrm{~cm} / 6 \mathrm{~cm}=4.6$. All cylinders were suspended axially two meters from the ground and detonated from the lower end, while the spheres were detonated from the center. The detonation chains investigated are detailed in Fig. 6 and the charge suspension methods are shown in Fig. 7. Photographic Instrumentation

A high-speed $16 \mathrm{~mm}$ motion picture camera photographed the first $400 \mathrm{msec}$ of the explosion and provided 4000 sequential frames. The initial 200 were used in overlay matching to oscilloscope horizontal sweep times. Electronic firing console operation was activated only when the required frame rate was reached; once activated, the programmed console fired physically separated bridgewires (light inputs for the light pipe and for the photographic record) in the necessary specified time sequence. Dimensional scaling was achieved simply by photographing, just shortly before the event, a marked 16-foot wooden rod held vertically alongside the suspended charge of high explosive. The interframe time of the photographic record was $0.1 \mathrm{msec}$ and the exposure time per frame was $.04 \mathrm{msec}$.

\section{Electronic Instrumentation}

Signal recording, time reference marks, and experimental control comprised the essential groups of the electronic instrumentation. Six Tektronix RM 31 oscilloscopes on each antenna channel provided the signal record. The specified oscilloscope sweep speeds and deflection sensitivities provided in general, an over-lapping dynamic range from initiation time to $20 \mathrm{msec}$, and $\pm .01- \pm 10$ volts in a typical test. Time reference marks on each oscilloscope record allow synchronization with the photographic records since both reference marks were derived from a single source - the bunker console. Numerous other electronic control functions were also supplied by bunker console operations. 
Results and Discussion

The value of the synchronous fast motion pictures only became evident in repeated viewings after the conclusion of the test series. In every test case, the electromagnetic signals appear to be associated with two distinct visible phenomena: First, the growth of the luminous explosion gases, expanding against the enclosing air volume; Second, the shock contact and its resulting reflection from the solid ground surface. As can be seen in the figures (and the summary film strip), the exploding cylinders in particular, developed vertical jets travelling both upward and downward from an expanding central gas "doughnut".

Each recorded em signal can thus be divided in time, into a corresponding first and second pulse. Their observed features follow:

\section{First Pulse}

1. Observed distinctly on $H / D=4.6$ and 2.0 (cylinders).

2. Displayed $\sim$ sinusoidal shape.

3. Remained nearly identical when suspension height doubled.

4. Occurred $\sim 0.3-0.5 \mathrm{msec}$ after detonation (before shock reaches ground).

5. Remained nearly constant in amplitude ( $\tilde{ \pm}-3$ volts at 8 meters).

6. Disappeared (virtually) on symetrical spherical events.

\section{Second Pulse}

1. Observed on all configurations detonated at 2 meters.

2. Disappeared on two detonations at 4 meters.

3. Occurred within $0.1 \mathrm{msec}$ of cloud brightening.

4. Correlated in time with luminous shock travel through cloud.

5. Observed temporary signal polarity reversal when ground contacted by luminous shock front.

It appears reasonable to conjecture from the modest amount of data analysis performed to date that only the first pulse is associated with the explosion proper, while the second pulse is dependent on the suspension height of the charge. 
The graphs in Fig. 8 show the "first pulse" $(H / D=4.6)$ and a7so a typical LRL individual record $(H / D=1.0)$. Fig. 9 exhibits the result that as the dimensional height of the cylinders is reduced, the large negative "second pulse" occurs nearer detonation time; the bottom graph $i l l u s t r a t e s$ the extremes of the $H / D$ ratios studied. Note also in this graph how the earlier ground arrival time of the lower jet obscures the "first pulse". The signal generated by the two test spheres are shown at the top in Fig. 10. The smaller sphere had 1/8 the mass of the larger $1.3 \mathrm{kgm}$ sphere; although this may be coincident, the signal amplitudes also vary by approximately the same ratio. The lower part of Fig. 10 answers the question that haunts most experimenters, "Can you reproduce your results?". Fig. 11 illustrates the large signal amplitude difference between charges of equal weight but different basic geometry (a H/D $=1.0$ cylinder and a sphere); the respective clouds produced are also markedly different. The bottom half of Fig. 11 displays our best agreement with the Soviet results. This relative comparison is hampered by the absence in their report of the amplitude calibration and the charge detonation time. The time base furnished was also somewhat unclear.

* Work performed under the auspices of the U.S. Atomic Energy Commission.

(1) EM Disturbances in Explosions, L. M. Gorshunov et a1., (Trans) U.S. Library of Congress, ARD Rpt \#68-88

(2) The Science of High Explosives, M. A. Cook, Reinhold (1958)

(3) The Detonation Electric Effect, B. Hayes (LASL), J.A.P. (39), 507 


\section{FIGURES}

(1) Schematic of Experiment

(2) Experimental arrangement (Sphere)

(3) Test Site - General View

(4) Instrumentation Bunker

(5) Test Charge Shapes

(6) Detonation firing chains

(7) Charge suspension and firing arrangement

(8) Typical "First Pulse" $H / D=4.6$ (Upper)

Complete record $H / D=1$ (Lower)

(9) Effects of $H / D$ ratio variation

(10) Spherical charge signals (Upper)

Signal Reproducibility (Lower)

(11) Comparison of cylinder and sphere (Upper)

Comparison with reported Soviet results (Lower) 


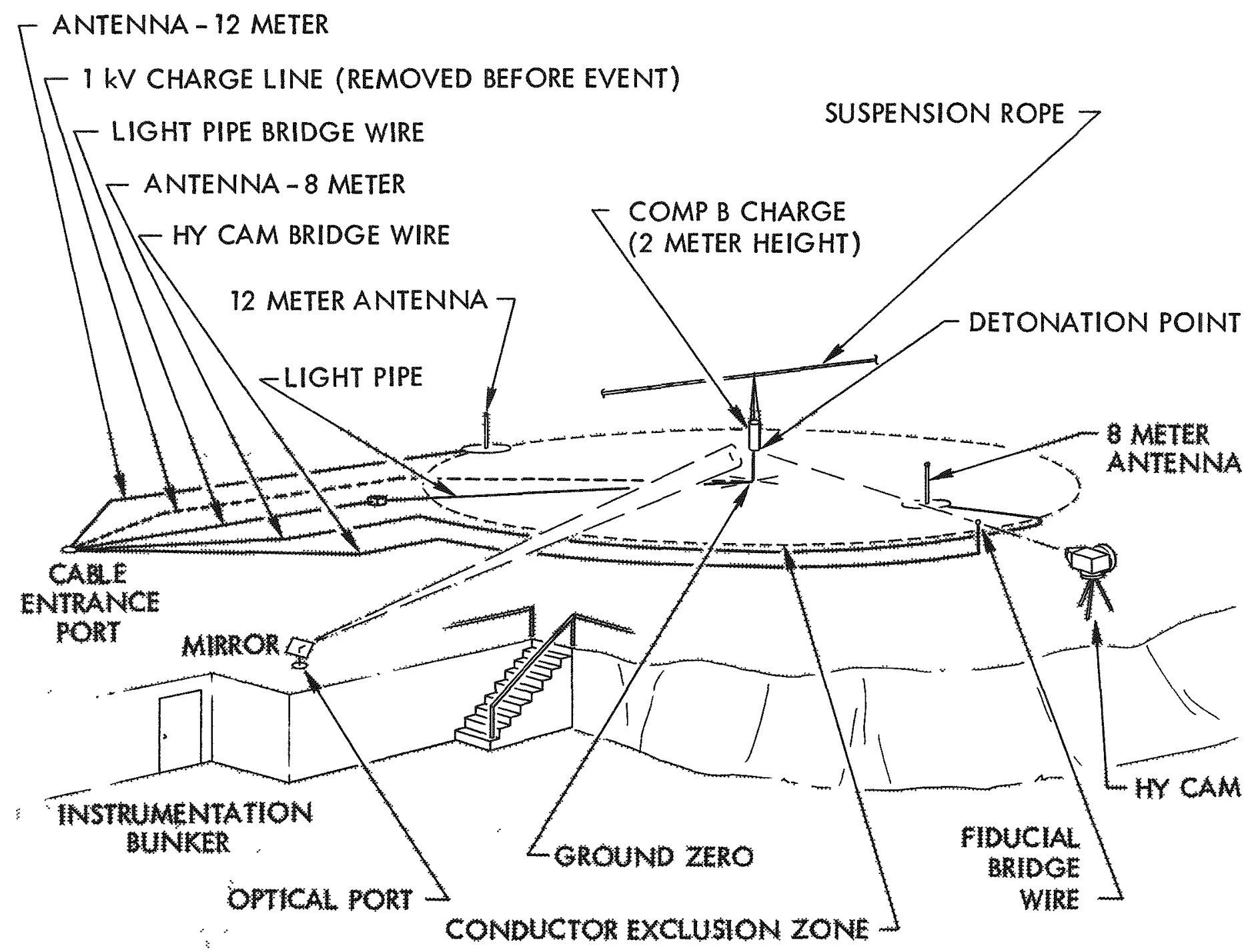

Fig. I SCHEMATIC DEPICTIVE VIEW OF EXPERIMENT 


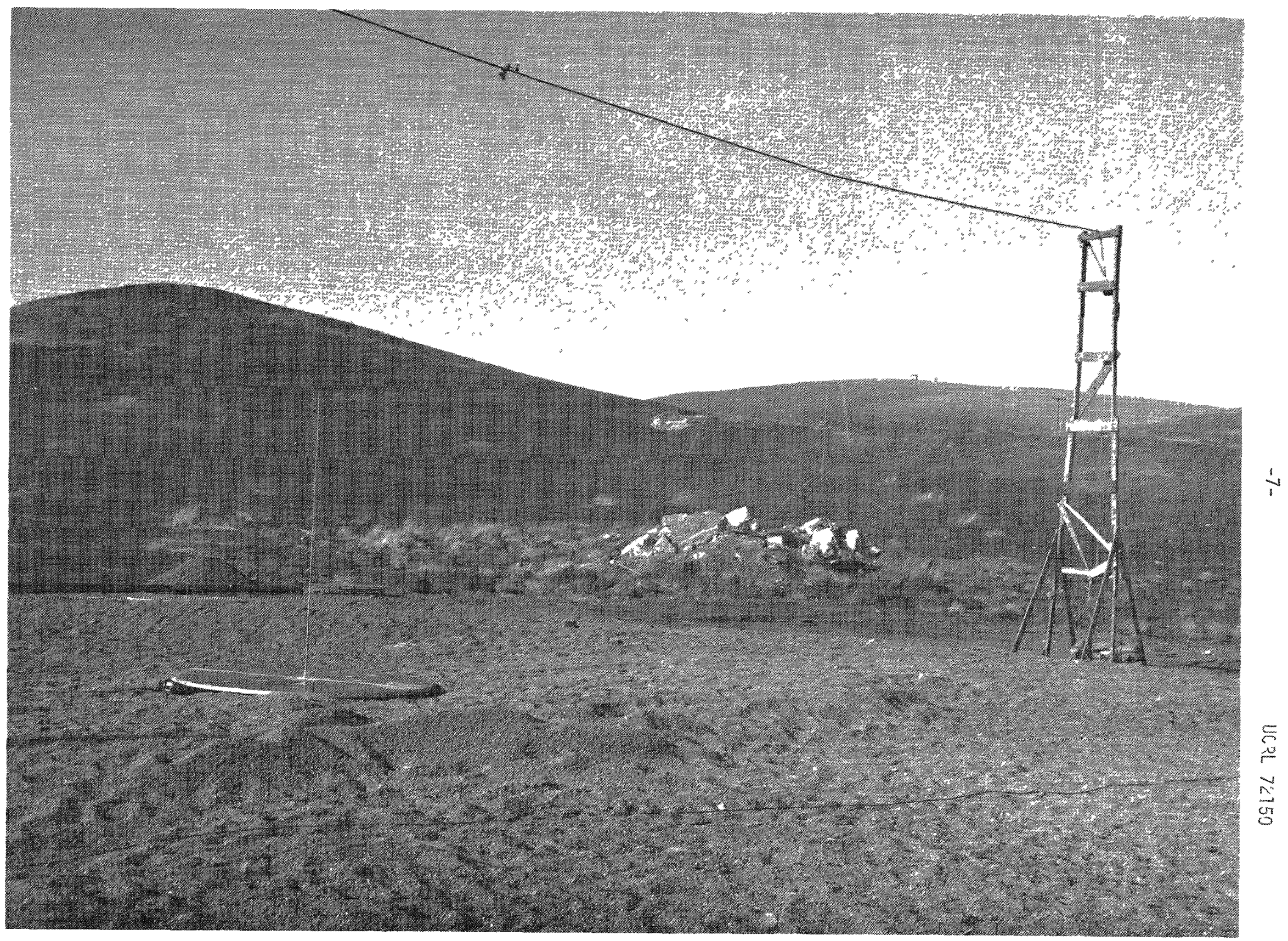

Fig. 2 Experimental Arrangement (sphere) 


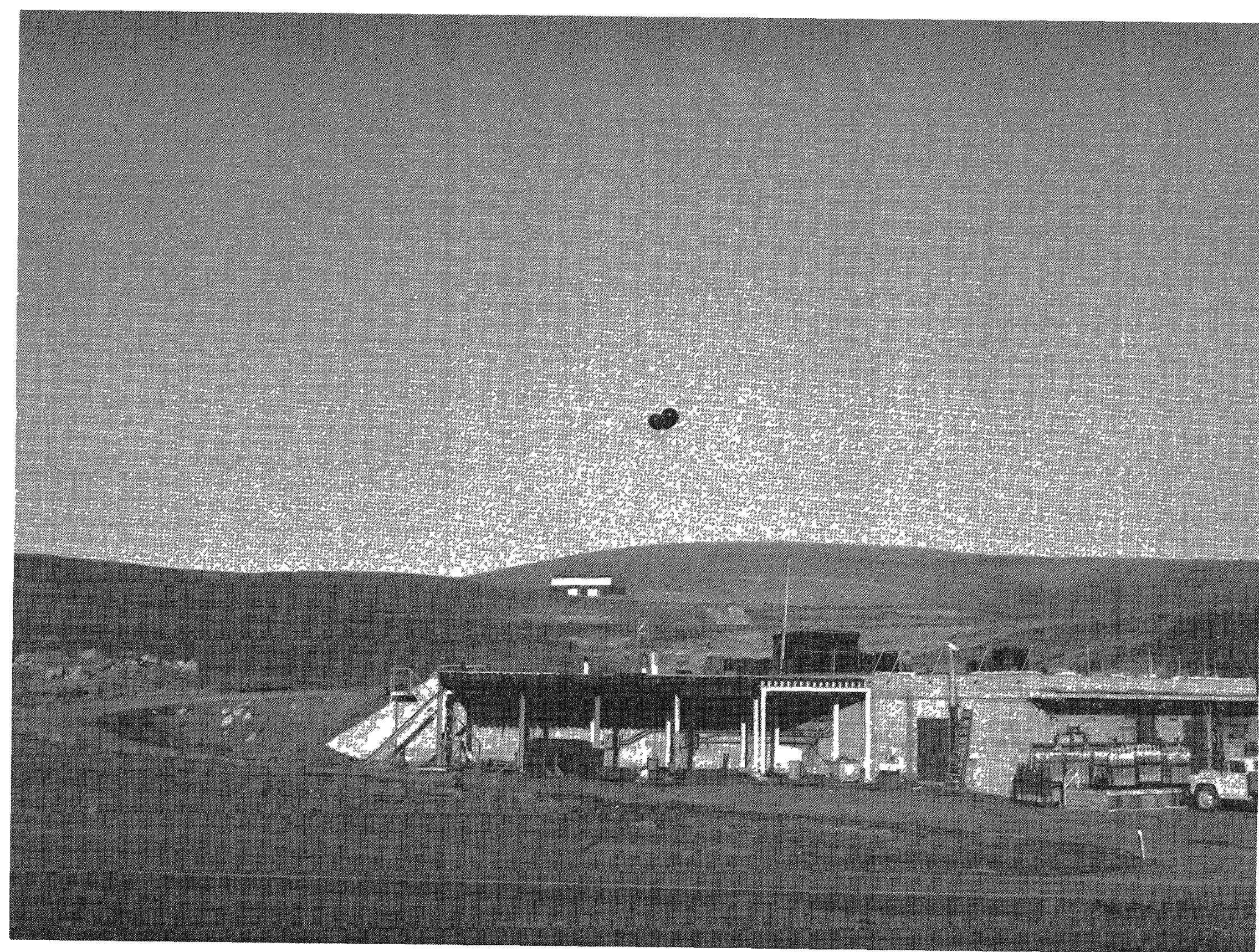




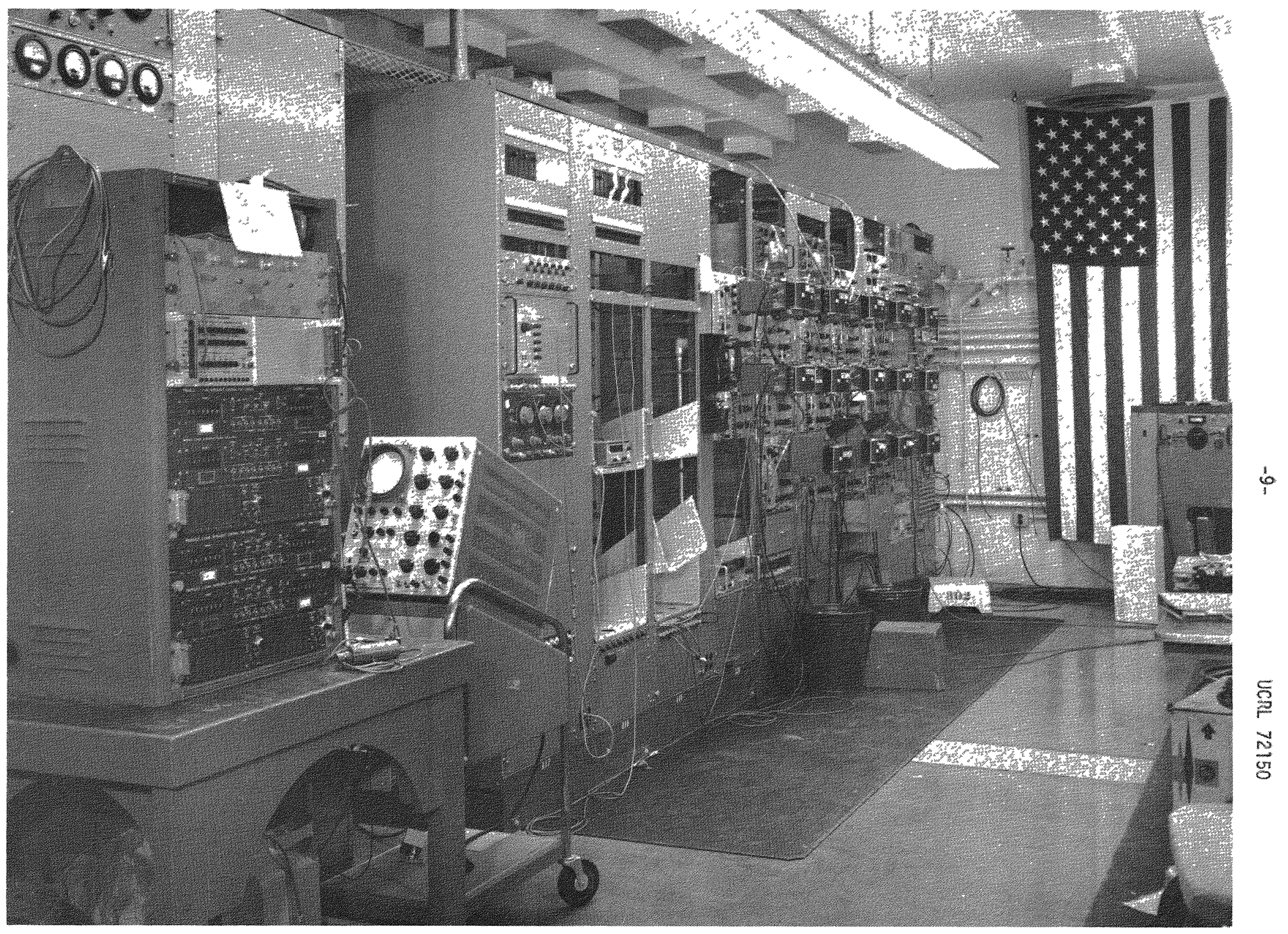

Fig. 4 Instrumentation Bunker 


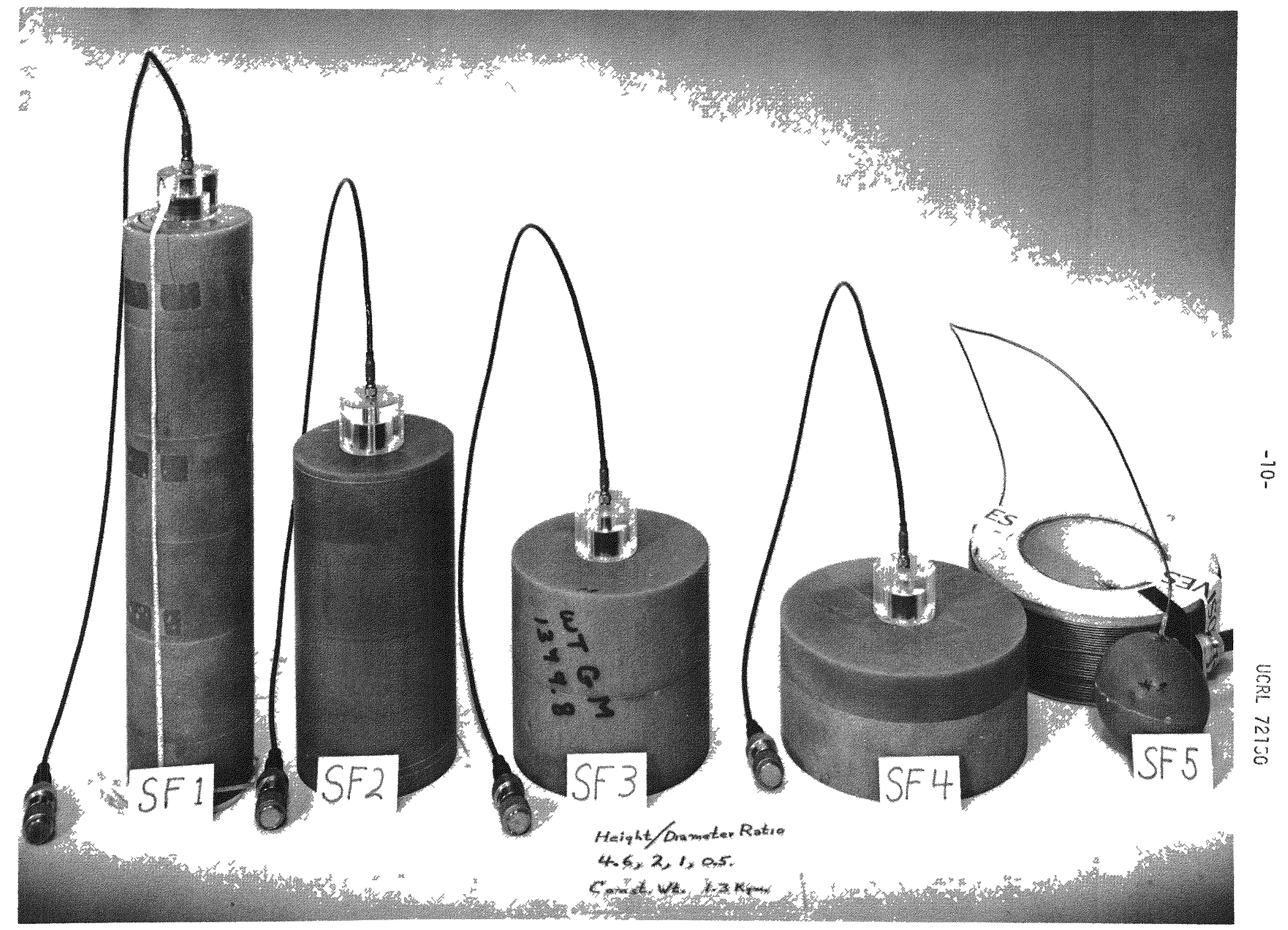

Fig. 5 Test Charge Shapes 

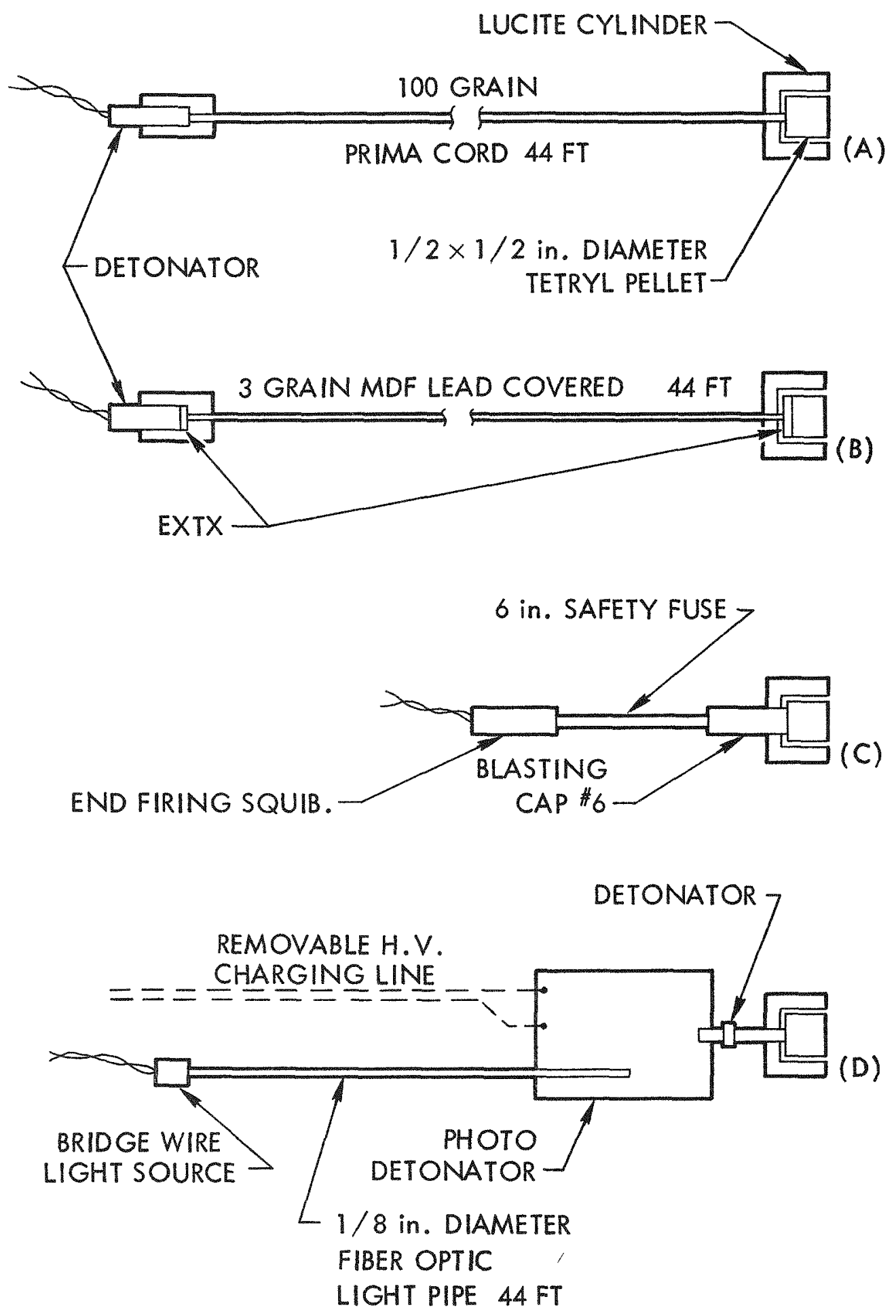

Fig. 6 FIRING CHAINS 


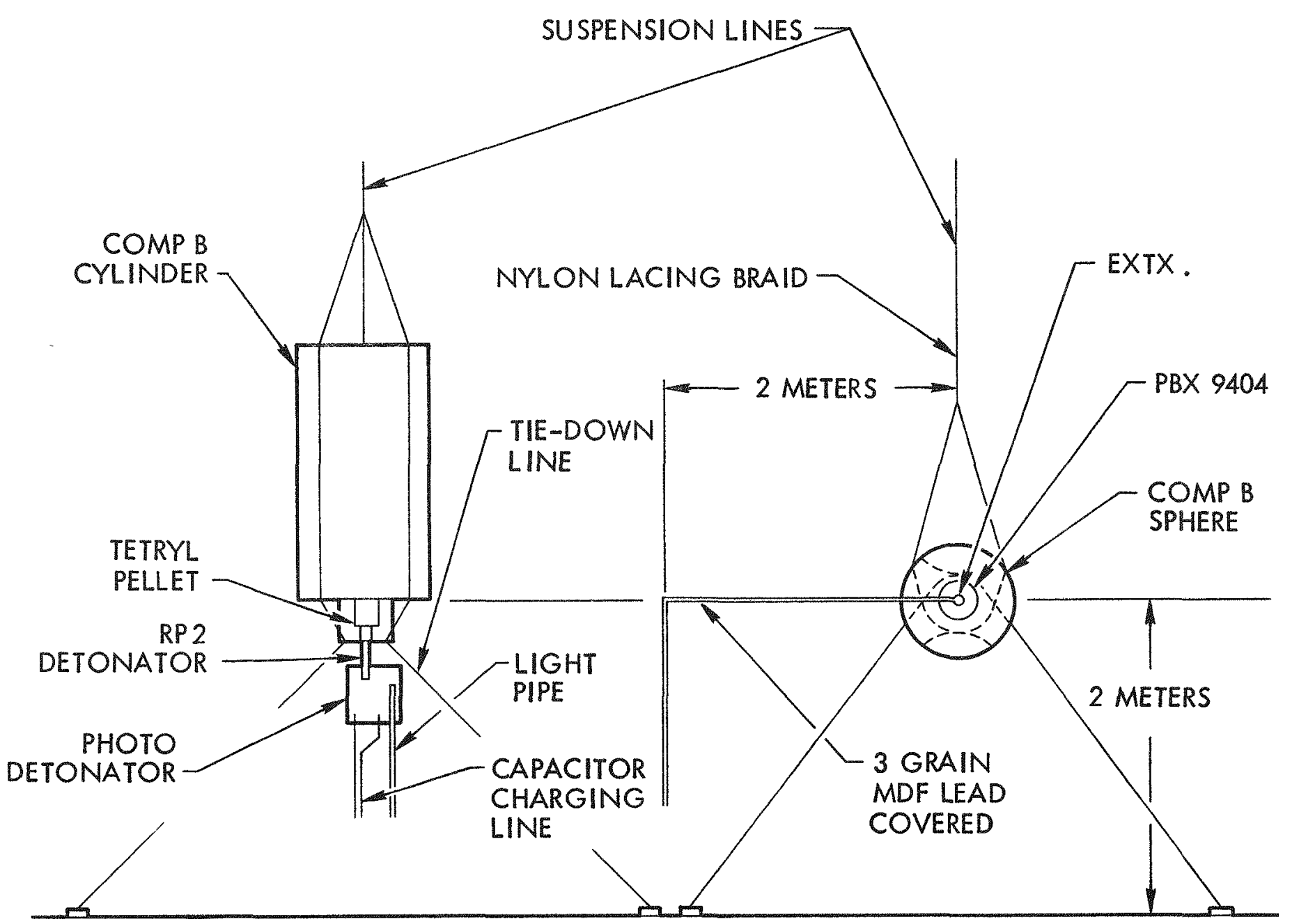

(A) CYLINDER

(B) SPHERE

Fig. 7 COMP B EXPLOSIVE SUSPENSION AND FIRING ARRANGMENT 

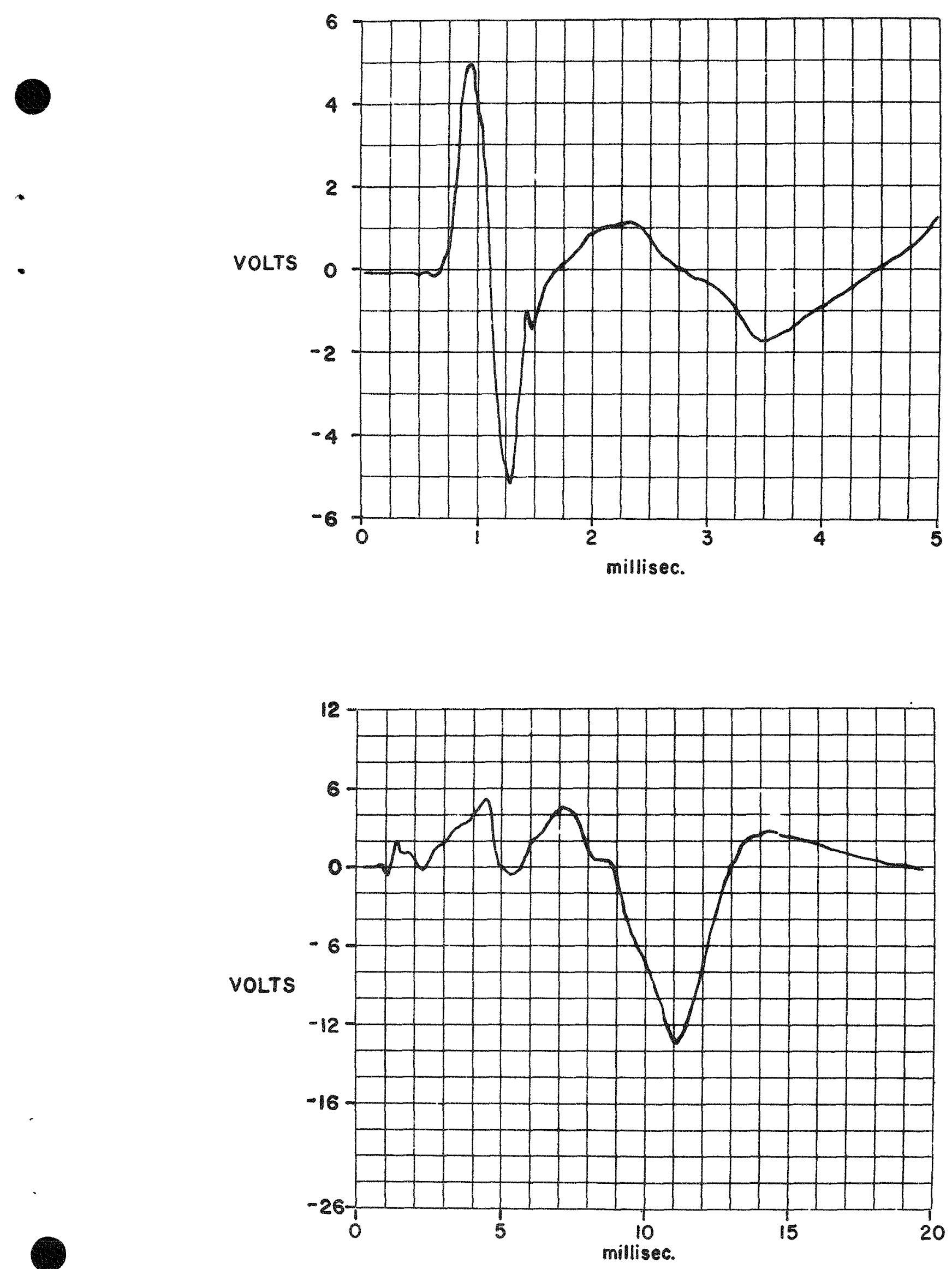

Fig. 8 TYPICAL "FIRST PULSE" H/D $=\$ .6$ (Upper) COMPLETE RECORD H/D $=1$ (Lower) 

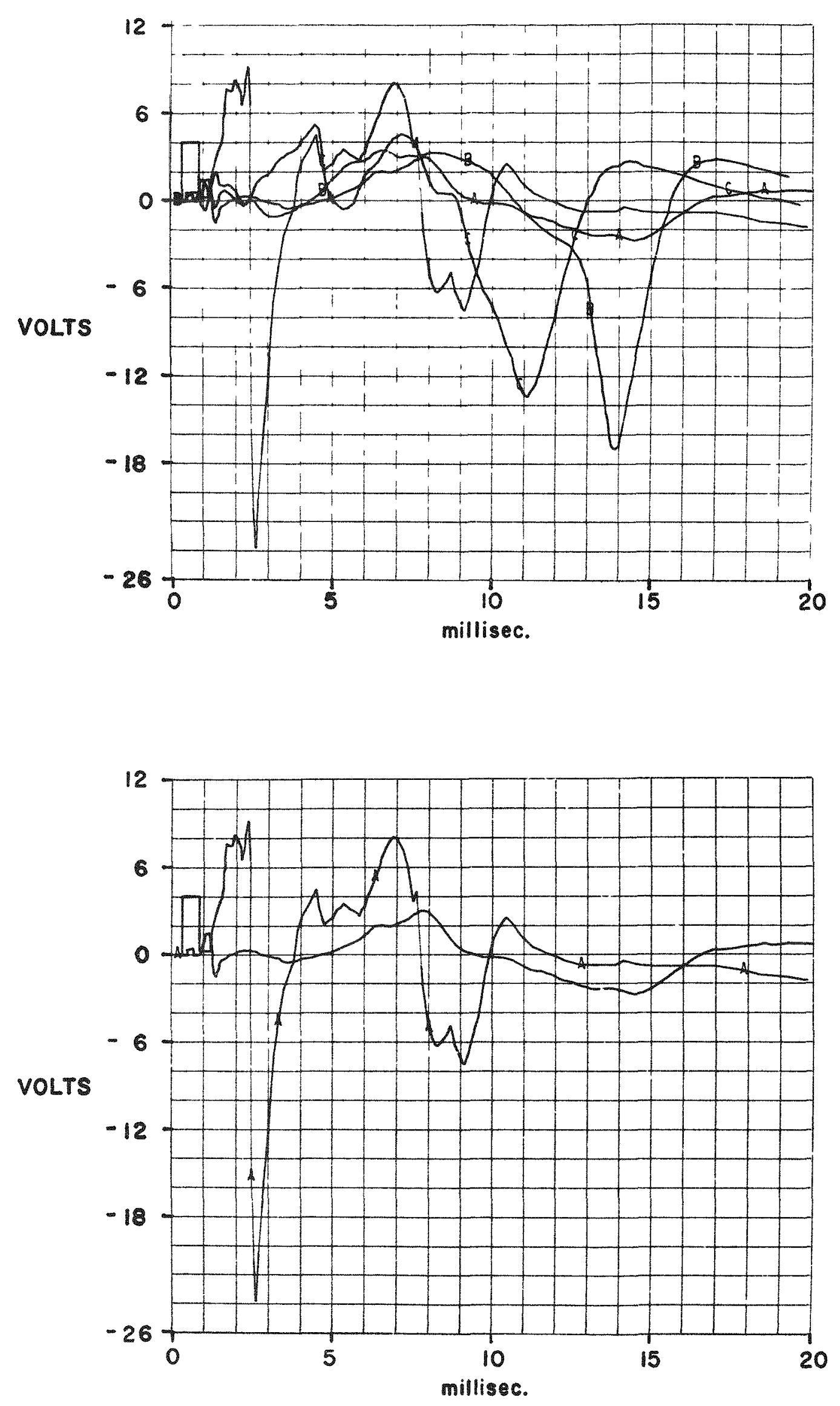

Fig. 9 EFFECTS OF H/D RATIO VARIATION 

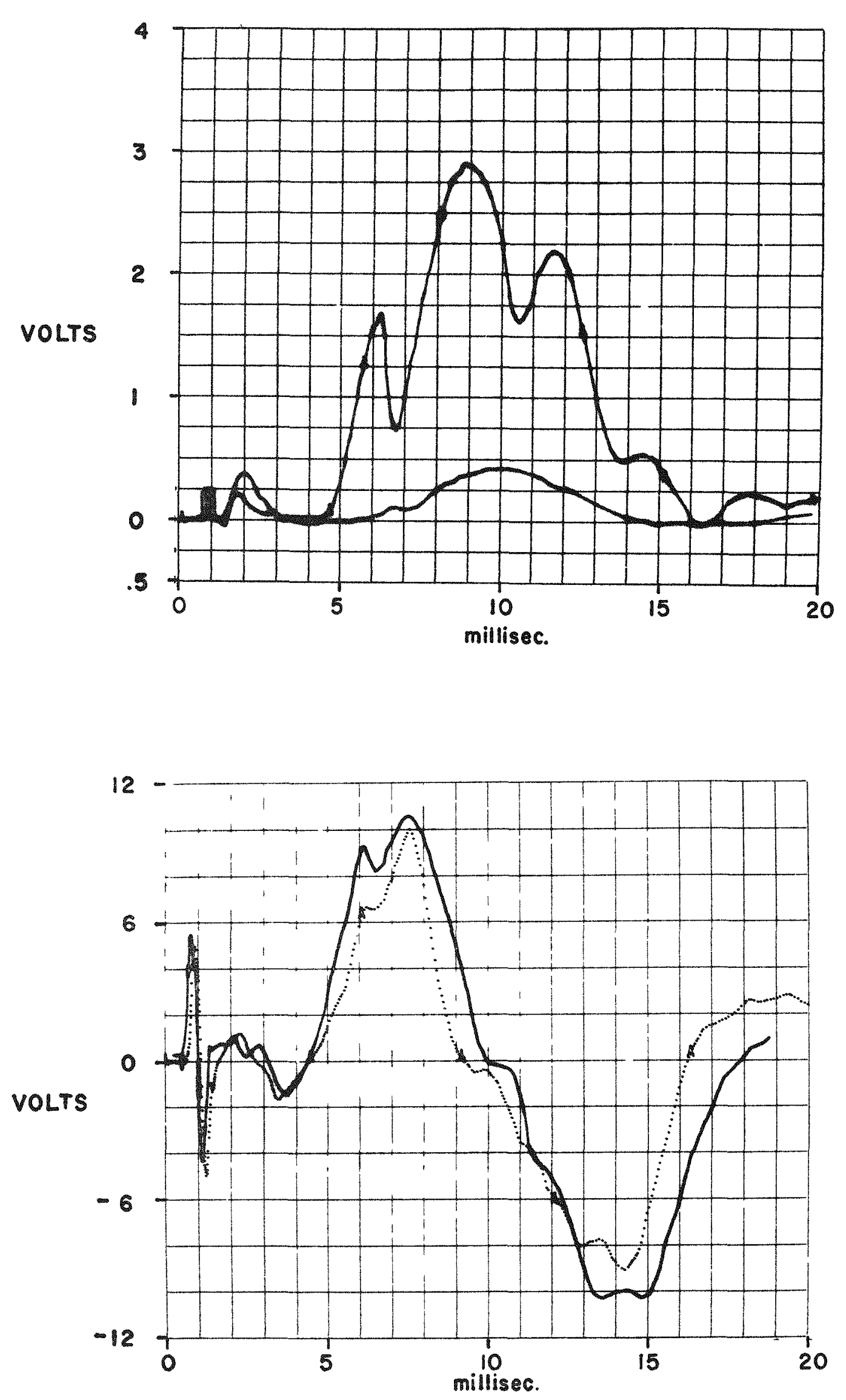

Fig. 10 SPHERICAL CHARGE SIGNALS (Upper) SIGNAL REPRODUCIBILITY (Lower) 

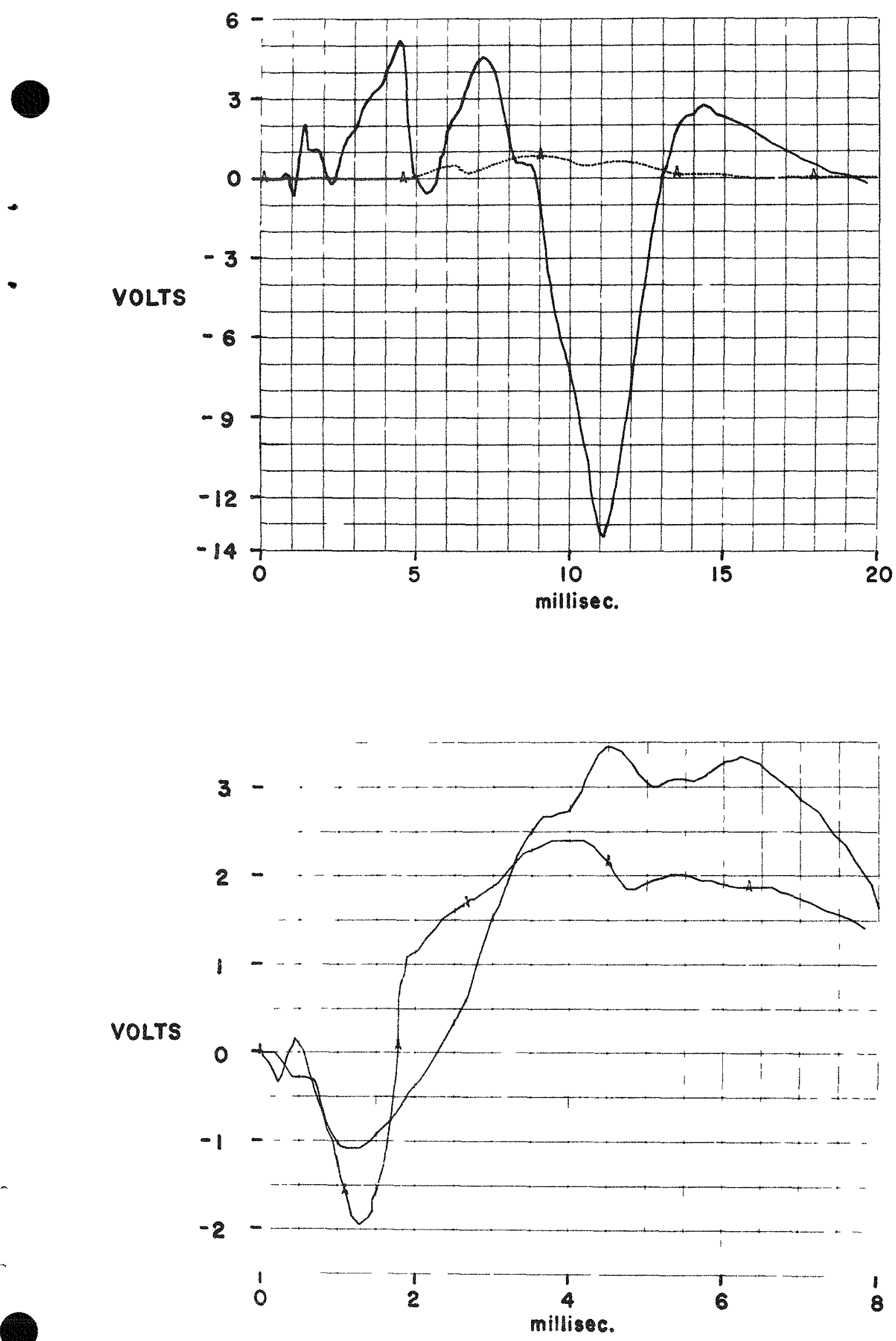

FIg 11 COMDARISON OF CYLINDER AND SPHERE (Upper) COMPARISON WITH REPORTED SOVIET RESULTS (Lower) 
DISTRIBUTION:

Internal

J. E. Carothers

E. Goldberg

M. Heinberg

E. James, Jr.

R. C. Maninger

L. C. Martin

M. M. May/D. C. Sewe11/A. T. Bieh1

D. C. Oakley

H. L. Reynolds

J. W. Rosengren/C. L. Teevan/D. E. Nielsen

C. W. Walker

L. F. Wouters

Technical Information Department

\section{Externa1}

Capt. Cal Allen (2)

DASA Hq., Washington, D. C.

Dr. V. C. Fryklund (2)

Advanced Research Projects Agency

Washington, D. C.

John S. Malik (2)

Los Alamos Scientific Laboratory

Los Alamos, New Mexico

David Nelson

Oak Ridge National Laboratory

Oak Ridge, Tenn.

A Makes any wartanty on epresentation expressed or inpted witt cospect to the accuracy completerness or usefuiness of the intormatic con

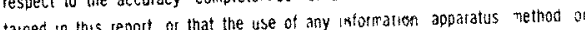
tained in this report or that the we ol inf ining privately owned ingtits of

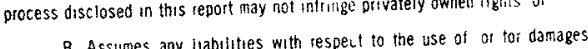
the respect to the use of of lor damages resulting from the use of any information apparatus method of process dis closed in this report

As used in the above "person actuing on behalf o" the Commission" includes any empioyee or contractor of the Commisstan or employee of such contractor to the extent that such employee of contactor of the Commission or emplayee of sucti contractor prepares disseminales or provides access to any information pursuane to his emiploynent of contract with the Commission or his employment with such contsacto 